\title{
Planificación y transformaciones urbanas de época augustea en Carthago Nova
}

\author{
Sebastián F. Ramallo AsENSIO \\ Universidad de Murcia \\ ra@um.es \\ María Milagrosa Ros SALA \\ Universidad de Murcia \\ milaros@um.es
}

\section{RESUMEN}

La configuración de los espacios urbanos ha sido en el tiempo escenario de los procesos sociales, económicos e ideológicos de las entidades poblacionales con voluntad de permanencia en el solar ocupado. La planificación administrativa de los sectores urbanos dedicados a usos públicos o privados se materializó en la necesaria habilitación de áreas residenciales privadas, artesanales o industriales y comerciales públicas, así como funerarias. A esta realidad no fue ajena la urbe de Carthago Nova en sus ocupaciones prerromana y romana; su progresión política y temporal registró toda una serie de transformaciones del entramado urbano y a ellas no fueron ajenos los condicionantes topográficos del medio físico primigenio y las contingencias ecológicas holocénicas. Poner en evidencia la conjunción de esta singularidad paleotopográfica, de origen geotectónico y dinámica geomorfológica, con las evidencias de importantes transformaciones operadas en época augustea, constituye el objetivo de este trabajo en el que se avanzan datos de un proceso de investigación en curso.

Palabras clave: Urbanismo. Paleotopografía. Fase augustea. Carthago Nova.

\section{Urban Planification and Transformation of Carthago Nova in Times of Augustus}

\begin{abstract}
The configuration of the urban sites has been setting of social, economic and ideological processes through the time, pertaining to the population entities willing to settle in the occupied site. The administrative planning of urban sectors involved in public or private uses was materialized in the necessary enablement of private or residential areas and public craft or industrial commercial and burial areas. The site of Carthago Nova was not exempt from this in its preRoman and Roman occupations. Its political and temporal progression showed a series of transformations of the urban fabric that were not unconnected to the topographic constraints of the primal physical environment and holocenic ecological contingencies. Bringing out the conjunction of this singular palaeotopography, which has a geomorphological dynamic and a geotectonic origin, with the evidence of significant transformations in Augustan period, is the focus of this work, in which data are shown from an ongoing research.
\end{abstract}

Key Words: Urban planning. Palaeotopography. Augustan period. Carthago Nova. 
Los dos dinteles que presiden los aditus del teatro romano de Carthago Nova constituyen, probablemente, uno de los ejemplos más explícitos de la relación de Carthago Nova con la familia imperial, y más concretamente con el Princeps; la dedicación a Cayo y Lucio Césares no deja lugar a dudas. ${ }^{1}$ Esta vinculación no se traduce sólo a través de estas dos piezas monumentales; al menos otras cuatro placas evocan pedestales dedicados a los hijos de M. Agripa y Julia, virtuales herederos del fundador del Imperio, probablemente coronados con las imágenes de estos. El propio yerno de Augusto es recordado en otro pedestal como patrono de la colonia ${ }^{2}$ y además figura como duunviro quinquenal en una acuñación urbana junto al propio emperador, magistratura delegada en los prefectos $Q$. Varius Hiberus y L. Bennius, respectivamente. ${ }^{3}$ Esta devoción se extiende también a otros miembros de la casa imperial, como Tiberio, que antes de su adopción por Augusto en el año 4 d.C., ocupó también la más alta magistratura cívica, delegando en C. Helvius Pollio, mientras que desconocemos quién fue el quinquenal a quien sustituyó como prefecto Hiberus, probablemente el mismo personaje de la emisión anterior, que le acompaña en la emisión. ${ }^{4}$ Por otra parte, también el futuro emperador, al igual que sucede con Agripa, forma parte de la lista de patronos elegidos por los habitantes de la colonia, una nómina que se amplía con destacados personajes del círculo imperial, como Iuba II, el rey de la Mauretania, o P. Silius Nerva, quien fue gobernador de la Citerior entre los años 19 y 16 a.C. La relación de la ciudad con la domus imperatoria se prolonga tras la muerte del fundador de la dinastía manifestándose en la presencia de los hijos de Germánico y Agripina, y por tanto nietos de Augusto y Agripa, Nero et Drusus Caesares, duunviros quinquenales hacia el año 27/29 d.C., 5 y de su hermano Calígula, quien detentó la misma magistratura, con anterioridad a la muerte de Tiberio, probablemente hacia el año 32/33 d.C. ${ }^{6}$

Por otra parte, la asociación en las inscripciones y monedas de los personajes distinguidos con el homenaje y los promotores de tales actos nos ha permitido conocer un poco mejor los nombres de las familias acaudaladas de la ciudad en época augustea y a algunos de sus miembros más ilustres. Uno de ellos debió de ser M. Postumius Albinus, que toma el nombre de una de las familias romanas de más rancio abolengo, y que dedica a Lucio César una placa con inscripción hallada en el teatro. Además, el mismo individuo aparece representado en un pedestal de travertino rojo, sustento, quizás, de una escultura ecuestre, hallado en la porticus post scaenam, donde bien pudo estar ubicado el monumento, muy probablemente dedicado al propio Lucio o

\footnotetext{
1 Este trabajo se ha realizado en el marco del Proyecto de Investigación, Carthago Nova: topografía y urbanística de una urbe mediterránea privilegiada (HAR2011-29330), del Ministerio de Economía y Competitividad, Dirección General de Proyectos de Investigación del Plan Nacional de I+D+i, parcialmente financiado con Fondos FEDER.

2 Косн 1979; Abascal - Ramallo 1997, 175-177, con la bibliografía anterior. Vid. en general, para la figura de Agripa en Hispania, RoDA 2004.

3 Esta emisión ha sido datada entre los años 17 y 14/13 a.C. Vid. Llorens 1994, 61; Llorens 2002, 69.

4 Llorens 1994, 62-63; Llorens 2002, 69, sugiere una datación de hacia el 9/8 a.C.

5 Ramallo 2003.

6 LloRens 1994, 75-76.
} 
a su hermano. ${ }^{7}$ (Fig. 1). En este sentido, es muy significativa la reaparición pocos años después del mismo personaje como IIvir quinquenal en una acuñación que porta como tipo un templo tetrástilo, con capiteles, posiblemente, corintios, basas áticas, pódium y la leyenda sobre el arquitrabe con la dedicación a Augusto. La emisión ha sido objeto de controversia, debatiéndose la investigación entre una cronología tardoaugustea o primo-tiberina. La primera opción, que en parte apoyaría la metalografía de la moneda aunque sin ser un aspecto concluyente, ${ }^{8}$ contravendría a las fuentes escritas que afirman cómo el propio Augusto se habría negado a la dedicación de templos a su persona en vida (Suetonio, Aug. 52). No obstante, a pesar de ese rechazo, parece cada vez más evidente que con anterioridad al 14 d.C. se erigieron espacios de culto dedicados a la figura del emperador, tanto en Hispania como en otras provincias del Imperio, si bien en el caso de los templos que conservan evidencias materiales el emperador Augusto es el que aparece asociado a la dea Roma. No vamos a entrar ahora en la discusión cronológica, tema que hemos abordado en otros trabajos. ${ }^{9}$ Sea como fuere, la exaltación y devoción a los jóvenes príncipes, preludia la expansión de un culto de carácter dinástico que muy pronto se concretará en el culto al propio emperador, organizado, al menos en el caso de Carthago Nova, a partir de época de Tiberio, como corrobora la inscripción dedicada a un desconocido personaje de la ciudad que fue prefecto de Nero et Druso Cesares, entre los años 23 y 29 d.C., y también, probablemente, el primer flamen divi Augusti. ${ }^{10}$

Ciertamente, la exaltación de la domus Augusta a través de esculturas e inscripciones es una constante en la mayor parte de las ciudades hispanas que alcanzan una condición jurídica privilegiada en época augustea o, incluso, anterior. Sin embargo, en el caso de Cartagena los homenajes tributados a sus componentes, y en particular a los dos nietos de Augusto, alcanzan un carácter y volumen excepcional, tanto cualitativa como cuantitativamente, ${ }^{11}$ que es difícil de explicar sólo como agradecimiento por un posible acto evergético. Esta ferviente exaltación hacia los virtuales herederos se manifiesta también en el altar de mármol de Luni que L. Iunius Paetus promueve

\footnotetext{
7 . La inscripción se conserva en tres fragmentos. El trozo de mayores dimensiones (n. inv. 6340-250-1), que constituye además la base, fue descubierto en noviembre de 1999 reutilizado en el contorno de una canalización moderna situada en la calle Orcel, junto al borde trasero de la plataforma de sustentación de la scaenae frons, sobre la cripta, con otros dos bloques del mismo material y dimensiones similares, que carecían de texto. Otro fragmento (mii.m.) fue hallado en el año 2005 en el derrumbe de una habitación bizantina situada en el corredor exterior que desemboca en el aditus oriental, mientras que el tercer trozo del pedestal, con el texto Postum, fue reutilizado en uno de los muros de época bizantina de esta misma estancia (UE. 10553). Interpunción triangular con el vértice hacia abajo en la línea inferior y en dirección opuesta en la superior. Las dimensiones son [57] x 69 x [84], aunque solo la anchura es segura ya que tanto en altura como en fondo el pedestal está incompleto. Uno de los bloques anepígrafos muestra una cavidad cuadrada de $22 \mathrm{~cm}$ de lado y 22 de profundidad, donde se insertaría el perno de apoyo de la escultura superpuesta. Conserva las dos últimas líneas de la inscripción con el texto: [------] / [M . ] POSTVMII - M[AXIMVS] / ET ALBINVS, lo que permite corroborar la restitución de la placa, en cuanto al plural del nomen y la existencia de dos cognomina. Las letras tienen 5 y $4 \mathrm{~cm}$, con un interlineado de $3 \mathrm{~cm}$ y un espacio vacío en la base de $29 \mathrm{~cm}$.

8 LlORENS 2002, 58; Ripollés - ABASCAL 1999, 51.

9 Ramallo 2007, 663-664.

10 Ramallo 2003, 201, donde sugerimos los nombres de M. Postumius Albinus o de su colega P. Turulius. Perea 2005, se inclina por el primero de los candidatos.

11 Vid. en general, CENERINI 2010, donde paradójicamente olvida los ejemplos de Carthago Nova.
} 
en honor de Cayo César, el mayor de los dos hermanos. ${ }^{12}$ Otro altar gemelo es consagrado a Fortuna por el mismo individuo, a quien, probablemente, hay que reconocer en una inscripción sobre caliza gris, empotrada en la actualidad en uno de los muros de cimentación de la iglesia de Santa María levantada sobre el extremo occidental de la cavea del teatro, junto a otro personaje de cognomen Gallus, que debía recordar alguna intervención evergética, sin que podamos relacionarla con el mismo edificio de espectáculos a pesar del lugar donde se encuentra reutilizada.

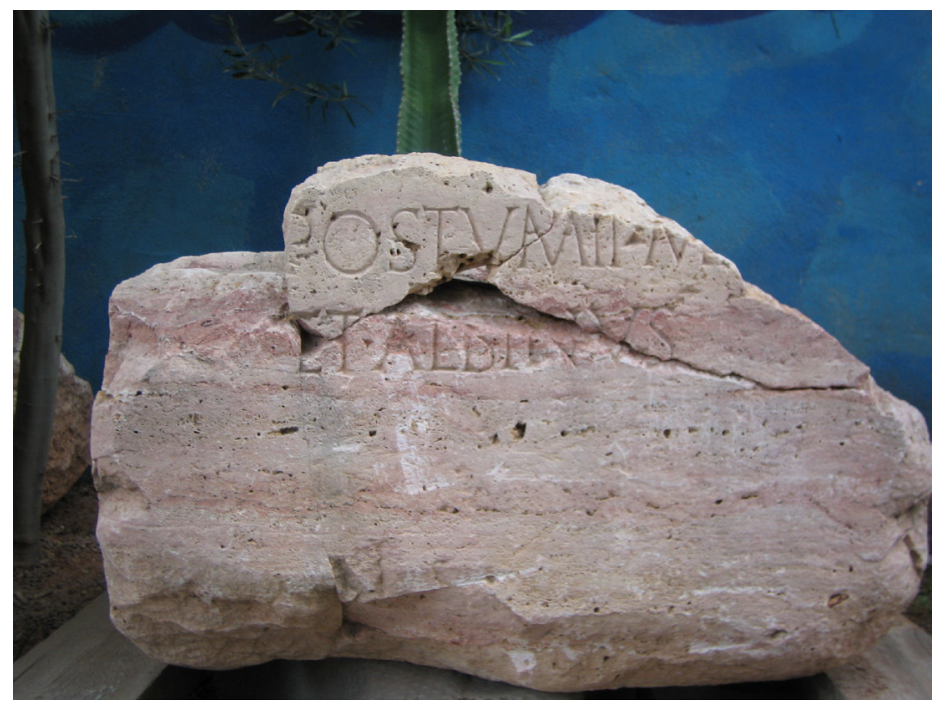

Fig. 1. Inscripción sobre pedestal de travertino rojo, con posible dedicación honorífica por Postumio Albino.

Con esta insistente adulación hacia la familia gobernante tal vez se querían borrar las dudas de un posible pasado pompeyano que se traduce en las fuentes y reflejan las inscripciones, especialmente dos fragmentos de brocal de pozo donde se menciona la construcción de una conducción hidráulica y las fuentes de suministro asociadas, por parte de un legatus o personaje vinculado al triunviro romano, hacia mediados del siglo I a.C. ${ }^{13}$

En este contexto analizado, el teatro es hasta la fecha el mejor exponente del proceso de transformación monumental que se produce en la ciudad en época augustea y de la envergadura de los trabajos acometidos para introducir en el nuevo urbanismo los elementos esenciales del paisaje urbano en una ciudad de condición jurídica

12 КосH 2009.

13 Ramallo - Murcia 2009; en contra, Amela 2012, quien sugiere la lectura más sencilla, que ya nosotros propusimos en el manuscrito original y que, modificamos, de acuerdo con los revisores del texto, que supone a Pompeyo Magno directamente como ejecutor de la obra. Sin embargo, al margen de que desconocemos intervenciones evergéticas del general fuera de la propia Roma, parece extraño que de haber sido el ejecutor de la obra el propio general, su cognomen Magnus aparezca abreviado en la forma Magn(i), algo que no ofrece dudas si se observa directamente la inscripción, y no completo. 
privilegiada. El edificio fue inaugurado entre los años 5 y 1 a.C., como corrobora el registro epigráfico, el estilo de los elementos arquitectónicos así como los contextos materiales hallados en los niveles de fundación. Para su construcción en la ladera noroccidental del Cerro de la Concepción, el más elevado y próximo a la fachada marítima, fue necesario destruir y terraplenar un barrio de carácter doméstico, escalonado y adaptado a la orografía irregular del monte, como atestigua la diferente orientación de las estructuras; sus trazas se han podido estudiar, sobre todo y hasta la fecha, en el extremo septentrional de la porticus post scaenam y en las rampas laterales de acceso al interior del edificio, tanto en su flanco oriental como occidental, ya que la cavea fue recortada casi en su totalidad en la ladera del cerro y la escena se levantó sobre un poderoso basamento de opus caementicium, anclado directamente sobre el sustrato rocoso, y con una fuerte pendiente en sentido este-oeste.

De este modo, en el extremo occidental y exterior del anillo de sillares que define el graderío, encontramos parte de una domus, con sus estructuras recortadas y apoyadas en la roca y alzados con muros de adobe sobre zócalos de mampostería. La parcial destrucción de las estructuras al erigir la iglesia medieval y el acceso desde la nave lateral a la cripta construida hacia 1876, dificultan la lectura e interpretación de la planta de la vivienda. Destaca entre los restos, una habitación pavimentada con un opus signinum decorado con teselas blancas, formando un motivo geométrico bien conocido en el repertorio de la ciudad, y la estancia contigua donde el falso techo ha sido recortado en sus laterales y aparece desplomado sobre el pavimento, siendo visible la impronta en negativo del cañizo que constituía el soporte del enfoscado de cal. (Fig. 2) En el lado opuesto de la cavea, las estructuras destruidas y colmatadas para la construcción de las rampas de acceso a la media y summa cavea son de menor entidad y se distribuyen en, al menos, dos terrazas distintas, con la habitaciones recortadas en la roca, forrada con muretes de mampostería y los alzados de adobe. No obstante, son los restos de la domus que amortiza y anula la construcción del brazo septentrional de la porticus post scaenam, los que mejor traducen la importancia dada al edificio de espectáculos como imagen emblemática de la nueva ciudad así como las grandes remodelaciones urbanas que este espacio de ocio implicó en lo que a la ciudad respecta. En este caso, se lleva a cabo la destrucción de una vivienda aterrazada, levantada probablemente en el tercer cuarto del siglo I a.C., y dotada de un rico programa decorativo, con pinturas que se pueden encuadrar dentro de un estilo de transición al tercer estilo precoz ${ }^{14}$ y pavimentos de signinum con incrustaciones marmóreas y ricas composiciones ornamentales.

No vamos a entrar aquí en detalles sobre la descripción del monumento y su programa ornamental, aspectos que han sido objeto de varias publicaciones. Desde el punto de vista arquitectónico, el teatro de Carthago Nova reproduce todos los componentes descritos por Vitrubio (V 9-3), al margen de la discusión que pueda plantear la aplicación del modelo teórico propuesto por el tratadista latino a su trazado. ${ }^{15} \mathrm{Su}$ construcción se inserta en una amplia serie de edificios teatrales levantados en época augustea, período en el cual se promueve y estimulan desde el poder central estos

14 FERnÁNDeZ 2008, 142.

15 Ramallo - Ruiz 1998, 105-110. 
espacios públicos, ${ }^{16}$ que tienen en los teatros de la Urbs, en particular en los erigidos por Pompeyo Magno entre el 61 y el 55 a.C. y por el propio Augusto aunque dedicado a su sobrino Marcello, dos de sus modelos más emblemáticos, ${ }^{17}$ si bien más ideológicos que arquitectónicos. Los dos edificios romanos aludidos caracterizan una arquitectura in plano levantada casi en su integridad sobre un armazón artificial de obra frente a los construidos parcialmente in montibus, esto es con parte de sus estructuras apoyadas en el terreno original, entre los que se encuentra el de Cartagena y la mayor parte de los edificios hispanos. Cavea, orchestra y cuerpo escénico constituyen los tres elementos imprescindibles, a los que se suman en los laterales, parascaenia y basilicae, ambientes que se convierten en el puente de unión entre el graderío y el escenario, a los que se añade tras este último un amplio espacio cuadrangular porticado por tres de sus lados.

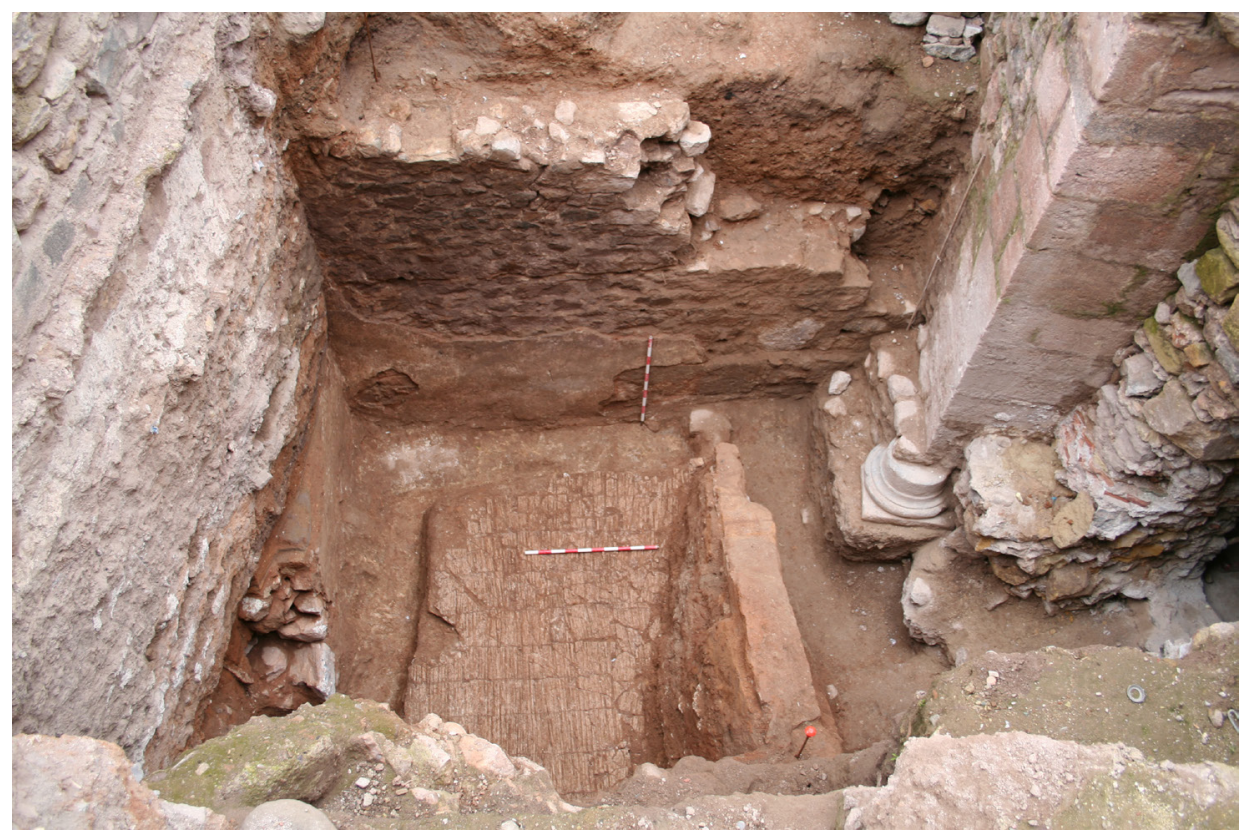

Fig. 2. Restos de una domus de época tardorrepublicana destruida para la construcción de las rampas de acceso al graderío del teatro en su flanco occidental.

La cavea está orientada al norte y se apoya casi de forma íntegra sobre la ladera recortada del monte; solo los flancos laterales, y en los tramos que corresponden a la media y summa cavea se apoyan sobre muros anulares y paralelos, que tienen una función exclusivamente tectónica ya que, de longitud decreciente desde arriba hacia abajo, se embuten contra la roca, lo que impide la circulación por las galerías resultantes. Tres escaleras radiales en la porción inferior del hemiciclo, cajeadas sobre

16 Gros 1990.

17 Vid. para la discusión sobre el papel desempeñado por ambos edificios, MonTERRoso 2010. 
bloques de caliza, y siete en los tramos central y superior, recortadas en piezas de arenisca, determinan, respectivamente, cuatro y ocho cunei. No se puede determinar con certeza el material pétreo empleado en el revestimiento de la roca que constituiría la epidermis o superficie del hemiciclo; sólo se ha conservado la primera grada, con su correspondiente reposapie que, al igual que el pasillo de separación con las gradas de la proedría, estaba realizada con bloques de piedra caliza gris. Por el contrario, las placas que se han conservado en el pasillo que divide la ima de la media cavea, son de arenisca, material que se utiliza también en el forro del balteus que separa ambos sectores y en algunos sillares fragmentados hallados sobre el graderío pero desplazados, seguramente, de su posición original.

El semicírculo original de la orchestra, apoyado directamente sobre el sustrato rocoso explanado, estaba pavimentado con un opus sectile de placas cuadradas de mármol, en forma de damero, combinado con lastras rectangulares en los extremos. El solado primigenio fue anulado, tras haber sufrido algunas restauraciones anteriores, por un pavimento de signinum liso, probablemente coincidiendo con una reconstrucción de la frons pulpiti, remodelación del hyposcaenium y renovación del foso del aulaeum, que se debió de producir hacia el primer tercio del siglo II d.C. Los sillares de arenisca del nuevo paramento articulado del proscaenium fueron decorados con un enlucido pintado en lugar del placado marmóreo que debió de recubrir la fábrica original. Es probable que corresponda a este momento el recubrimiento pictórico de los elementos del frente escénico. Efectivamente, algunas de las basas del primer piso conservan visibles trazas de una fina película de preparación recubierta con un pigmento de color ocre dorado, terminación que se aprecia también en varios capiteles y molduras del pódium; en algunos capiteles esta película ocre se superpone a otra capa más antigua de color rojo. Por otra parte, en los bloques del pódium del segundo piso, se han conservado trazas donde la pintura roja se superpone -a veces parece que se combina- a otra de pigmentación azul; ambas son recubiertas por la capa ocre dorado. ${ }^{18}$

Como sucede en la mayor parte de los edificios de características semejantes, es en la fachada escénica y en los materiales que la conforman donde mejor se aprecia la envergadura y el cuidado e interés puesto en la ejecución de esta obra. En su alzado se combinan mármoles blancos procedentes de las canteras de Luni que son empleados en la labra de capiteles, basas y, posiblemente, en las placas de revestimiento del entablamento, junto a travertinos rojos procedentes de las canteras de La Almagra (Mula), con los que se alzan los fustes y bloques de caliza gris de procedencia local, empleados en los basamentos sobre los que apoyan los órdenes arquitectónicos. Es muy significativa la abundancia de marcas o siglas en las piezas que conforman el puzle de la fachada, incisas sobre todo, pero también pintadas. La numeración que de ellas se desprende, especialmente abundante en los tambores de fuste, se podría relacionar con indicaciones para el montaje y colocación de las piezas. Es significativa, en este sentido, la reiteración y coincidencia del número IV con los sumoscapos de la columna, en tanto que los numerales II y III coinciden con la parte central, mientras

18 Ramallo et aliI 2010, 224-225. 
que el I suele coincidir con los imoscapos de la columna. En cualquier caso, es un tema abierto a la discusión sobre el que existen varias propuestas alternativas. ${ }^{19}$

Por otra parte, contrasta la calidad de los materiales pétreos y la cuidada ejecución de las fábricas utilizadas en el teatro, particularmente en el cuerpo escénico y en la orchestra, con lo que sucede en la porticus post scaenam, donde se utiliza casi de forma exclusiva, tanto para los paramentos murarios como para los elementos arquitectónicos, la arenisca amarillenta de procedencia local revestida de estuco pintado. Es muy significativo a este respecto, un bloque de arquitrabe/friso del pórtico que cierra el flanco oriental, donde la inscripción aparece grabada directamente sobre la misma pieza, remarcada con pintura roja. En el texto conservado sólo se lee $P R[---]$, inicial que podría corresponder a términos como princeps, quizás en una nueva alusión a los jóvenes nietos de Augusto, omnipresentes en otros puntos del edificio teatral, pero también al cargo de praefectus, bien atestiguado a través del registro epigráfico y en la serie de acuñaciones locales en la titulación de ciertos personajes de la elite local que ejercieron la representación de los miembros de la casa imperial honrados con el duunvirato quinquenal. No hay que descartar otras alternativas, como que formara parte del cognomen del promotor de la obra. En este sentido, conviene recordar, aunque sólo sea a modo de sugerencia, una inscripción, fragmentada y perdida en gran parte, donde un individuo de nombre $C$. Ptotius Princeps adquiere unas insulae e hizo de su dinero crypta et porticus. De ser cierta esta restitución, transmitida por los primeros editores del siglo XVIII, el texto podría aludir, tanto al espacio situado tras la escena del teatro, donde ambos elementos están atestiguados y donde las excavaciones han permitido atestiguar, como ya se ha señalado más arriba, la existencia de un barrio de casas destruido para la construcción del monumento, como al área del foro, donde ambas piezas, cripta y pórtico, podían formar parte del entramado monumental.

Al margen de estas consideraciones, las limitaciones constructivas y, en consecuencia, pecuniarias de este sector del monumento romano, se manifiestan con claridad en la talla de los elementos arquitectónicos que configuraban las columnatas que cerraban los pórticos que delimitaban lateralmente el espacio ajardinado. Las basas presentan notables diferencias unas de otras, si bien predomina el tipo ático sin plinto, con toros de igual diámetro y escocia reducida. La misma modestia y escasa pericia se aprecia también en los capiteles, jónicos en la galería exterior, y corintios en las columnas que dividen el espacio en dos naves. La terminación estucada de las piezas y, tal vez los recursos limitados, no son argumentos suficientes para justificar la mediocridad de la obra. Todos estos detalles nos llevaron a pensar en una diacronía entre ambas partes del monumento, sin embargo los detalles constructivos y los contextos materiales asociados a los niveles de construcción parecen refrendar una identidad cronológica.

19 Vid. para su interpretación como marcas relacionadas con los procesos de extracción y contabilidad en SOLER 2012, 207, n. 58. 


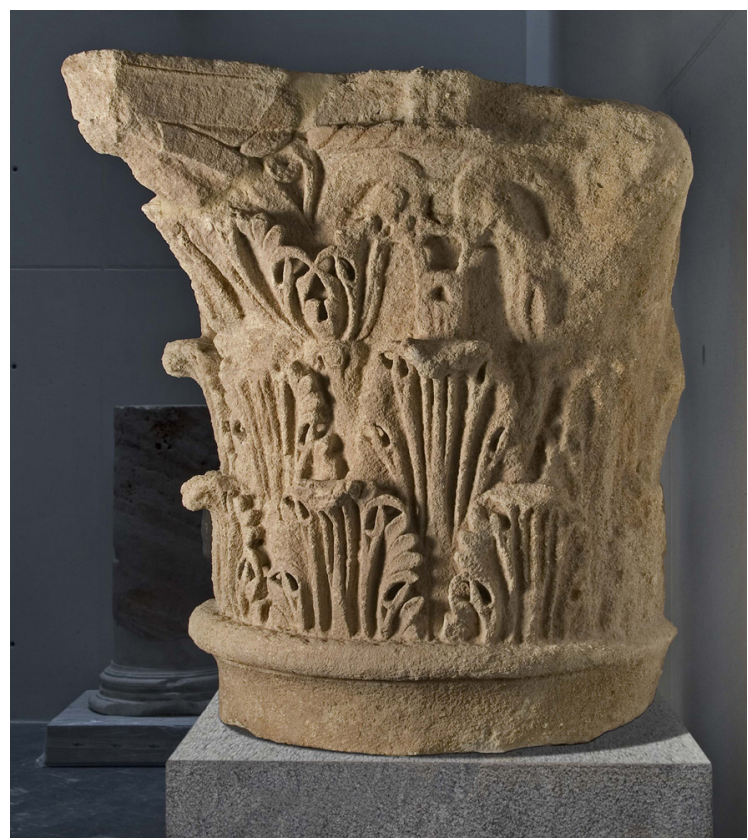

Fig. 3. Capitel corintio canónico labrado en arenisca procedente de la galería posterior del cuerpo escénico.

Así las cosas, se podría pensar en la reutilización de material procedente de construcciones precedentes destruidas para la construcción del nuevo complejo, al que se daría una cierta unidad con los estucados del acabado. En este sentido, habría que entender el capitel corintio de la galería interior, desproporcionado y con una sola corona de hojas de acanto, tal vez como resultado de su readaptación a la nueva fábrica. Sólo se distancia de esta norma un capitel corintio, de mayor tamaño y una labra mucho más cuidada, que formaba parte de la galería porticada situada sobre la cripta que, adosaba al paramento de opus caementicium de la scaenae frons, cerraba la porticus post scaenam por su frente meridional, procurando un aspecto monumental, a modo de fachada, al postscaenium. El capitel en cuestión, trabajado sobre arenisca local, presenta todos los elementos que configuran el tipo canónico: dos coronas de hojas de acanto, formadas con lóbulos que se recogen en torno a la costilla central delimitada por profundas oquedades que llegan hasta la base, caulículos ligeramente inclinados de donde nacen hélices y volutas, envueltas en una doble hoja de acanto; un grueso baquetón semicircular separa el kalathos del sumoscapo de la columna, labrado en el mismo bloque. En este caso, tanto en altura como en estilo y tipología se intenta reproducir las características de los capiteles marmóreos del frente escénico. El tallo ondulado que ocupa sobre el kalathos el espacio que queda entre hélices y volutas remite a la pequeña roseta que caracteriza a los capiteles vinculados al denominado "estilo del Segundo Triunvirato", y que vemos plenamente desarrollada en los ejemplares marmóreos del primer piso de la scaenae frons (Fig. 3). En su conjunto, 
el capitel, con claros paralelos en ejemplares de las últimas décadas del siglo I a.C., nos procura los rasgos esenciales de una arquitectura estucada y pintada que, precede y convive con la temprana arquitectura del mármol que comienza a difundirse en el ámbito provincial en época medio-augustea, siendo el teatro de Cartagena uno de los ejemplos más tempranos.

Otro testimonio excepcional de la actividad de los talleres locales en el ámbito de la arquitectura pública augustea se muestra en el porticado que cierra el borde meridional del espacio forense. En este caso, nos encontramos con basas áticas sin plinto, labradas en caliza gris, que muestran como rasgo distintivo una estrecha escocia entre dos toros de perfil semicircular e idéntico diámetro; sobre la basa se alza un fuste de arenisca revestido por un grueso enlucido pintado de rojo, coronándose la columna con un capitel toscano compuesto por un ábaco cuadrado, equino de sección en cuarto de círculo prolongado en vertical, listel, amplio caveto y sumoscapo, molduras todas ellas que se reproducen también, en sentido inverso, en un conjunto de basas descubiertas en distintos puntos de la ciudad. Probablemente con este edificio habría que relacionar un conjunto de antefijas con motivos vinculados a la propaganda oficial, tales como máscaras teatrales y Victoria con trofeo flanqueada por dos capricornios, que hay que interpretar en clave simbólica. ${ }^{20}$ Por otra parte, la sustitución de las basas toscanas por el tipo ático sin plinto, debió de ser frecuente desde finales de la República, y se ha venido considerando como una variante del tipo provincial del orden toscano. ${ }^{21}$ No obstante, las mismas características de labra que vemos en los órdenes de la porticus post scaenam del teatro y en el edificio que delimita el foro por el sur, se reproducen, ya en ámbito doméstico, en la denominada "Casa de Salvius", situada en la ladera baja occidental del Cerro de Despeñaperros, en un barrio de carácter doméstico remodelado en época augustea con la construcción de nuevos inmuebles superpuestos a las estructuras tardorrepublicanas. En este caso, los capiteles corintios, labrados en arenisca local y estucada, al igual que el resto de la columna, presentan rasgos arcaizantes, como las rosetas de cuatro pétalos que veíamos en las piezas del teatro, y atestiguan la presencia de artesanos que desde fechas tempranas introducen en la ciudad los parámetros del corintio canónico que a partir de época augustea se impondrá, asociado al mármol, en las construcciones de carácter religioso. ${ }^{22}$ No obstante, el orden jónico mantendrá toda su vigencia en la arquitectura de este momento, al igual, probablemente, que el orden toscano reservado para porticados y construcciones de carácter secundario.

En este sentido, otro rasgo asociado al proceso de renovación de la ciudad en época augustea va a ser la introducción de nuevos materiales pétreos, como el travertino rojo, cuyas canteras se hallaban situadas a más de $70 \mathrm{~km}$ de la ciudad, y que ya hemos visto utilizado en las columnas de la fachada del teatro. Son numerosos los capiteles jónicos labrados sobre esta roca, tanto en su variante "jónico-itálica" o con cuatro caras iguales y volutas en diagonal, como en su forma canónica, con dos frentes y cojinetes laterales, y lisos, constituyendo uno de los mejores ejemplos de

\footnotetext{
20 Noguera ET ALII 2009, 266-267.

21 Broise 1969, 17.

22 MADRID ET ALII 2005, 143-144.
} 
esa renovación urbanística. Al margen de estas series, destaca un conjunto híbrido representado por tres capiteles, que hemos definido como jónicos de aire corintizante, que se caracterizan por un doble frente definido mediante dos cintas serpentiformes cuyos extremos superiores constituyen las volutas, mientras que de los inferiores brotan sendas palmetas de cuatro pétalos que encuadran un motivo fitomorfo situado en el eje axial. Son piezas que guardan una cierta relación formal con los capiteles figurados y de los que no hemos encontrado paralelos claros, salvo los ejemplares de la basílica de Segobriga, ${ }^{23}$ que han sido fechados en época augustea, y que atestiguan la vitalidad de los talleres de Carthago Nova fuera de su ámbito más inmediato. Además de estos capiteles, cuyo emplazamiento original es imposible precisar debido a las circunstancias del hallazgo, testimonian la importancia de este material en la arquitectura pública y oficial varios tambores de fuste cuyo diámetro supera los 0,90 $\mathrm{m}$, y que debieron de formar parte de construcciones de carácter religioso.

La construcción del edificio de espectáculos constituye el punto álgido de un proceso que se inicia en las décadas precedentes con la construcción o reconstrucción de nuevos paños de muralla y con la adecuación y reestructuración de la trama viaria. La renovación del cerco defensivo se atestigua a través de un numeroso lote de inscripciones que, en conjunto, se pueden encuadrar dentro de la segunda mitad del siglo I a.C., aunque en su mayor parte deben ser ubicadas en el último tercio de dicha centuria. Del registro epigráfico podemos determinar el nombre de algunos de los magistrados, duunviros y ediles que participaron en dicho proceso, si bien no podemos determinar si se trata de una participación de carácter evergético o, por el contrario, corresponde a la ejecución y supervisión de la obra impulsada por el senado local. De determinadas inscripciones se puede deducir también la alternancia de paños de muro recto con turris, así como de una puerta de nombre Popilia. En algunos tramos, al menos, la fábrica se haría a fundamentis. ${ }^{24}$

A nivel arqueológico, por el contrario, las evidencias son mucho más reducidas, lo que impide concretar su trazado, tanto sobre las laderas de las cinco colinas que constriñen el espacio urbano como en los tramos intermedios. En este sentido, es especialmente controvertida la posible existencia de un tramo en la fachada marítima, relacionada con las actividades portuarias. La información arqueológica disponible nos habla de un frente monumentalizado en época tardorrepublicana, probablemente en el primer tercio del siglo I a.C., aunque no se pueda descartar una cronología ligeramente posterior, que se plasma en la erección de un frente porticado en el flanco occidental de la ciudad, en contacto con las áreas portuarias, cuyo alzado conocemos en dos tramos distintos, respectivamente descubiertos en la calle Morería Baja, situado en el extremo septentrional, y el segundo, situado en el extremo opuesto, esto es en la Plaza del Ayuntamiento. Tanto en un caso como en otro, se han empleado basas toscanas de plinto circular que apoyan sobre una gruesa zapata cuadrangular. Por el contrario, más difícil es definir como parte del cerco defensivo, si es que realmente existió en este sector, un paramento de 1,85 m de grosor, hallado en la calle Mayor,

23 TRUNK 2008, 28-30.

24 Abascal - Ramallo 1997, 81-113; Díaz 2008, quien propone fechar algunos de los epígrafes a mediados del s. I a.C. 
esquina Medieras, al que se adosan parte de las habitaciones de una domus erigida, según sus excavadores, a inicios del siglo I d.C. ${ }^{25}$

Con esta muralla hemos relacionado un paramento de más de $15 \mathrm{~m}$ de longitud y $1,10 / 1,20$ de anchura, construido de mampostería y reforzado por tirantes perpendiculares que se superponen a los sillares de cimentación de la muralla púnica, previamente desmantelada, descubierto en la ladera occidental del Cerro de la Concepción, a espaldas del anillo exterior de la cavea del teatro. Una portezuela abierta en el extremo nororiental del tramo excavado permite intuir la existencia de un camino secundario que bordearía la ladera meridional del Cerro; un camino que se perpetuaría en épocas posteriores como parece atestiguar la cartografía de época moderna. Los contextos materiales que aparecen asociados a los niveles constructivos se fechan entre los años 5030 a.C., destacando la práctica ausencia de terra sigillata itálica, fenómeno que también se observa en los paquetes de colmatación sobre los que se superpone el enlosado del nuevo viario augusteo. ${ }^{26}$

La renovación del entramado viario es otra de las consecuencias de la remodelación augustea. No obstante, al menos parte de los ejes que atraviesan la ciudad debieron de conservar el recorrido de las viejas cazadas barquido/republicanas, si bien recrecidas sobre un potente relleno de nivelación y pavimentadas con losas poligonales de caliza gris cuidadosamente ensambladas. Sin duda, durante esta fase se completaron y ampliaron los trabajos de adecuación de una topografía compleja que imponía sus límites al desarrollo urbano. Estos condicionantes se solventaron, en parte ya durante época bárquida, mediante la construcción de poderosos muros de aterrazamiento en las laderas interiores de las colinas que, combinados con recortes en el sustrato rocoso, y rellenos artificiales creaban terrazas artificiales a cota de roca, por donde discurrían las vías urbanas, en tanto que las viviendas adecuaban sus estructuras a esa topografía escalonada. En este sentido, las fuentes literarias insisten y resaltan los aspectos positivos de su singular orografía, descrita con detalle en los textos. Recordemos que Estrabón (III 4.6), en época augustea, ensalza su posición fuerte, sus murallas, sus puertos, su laguna, sus minas de plata y su salazón, pero esas virtudes, que hacen de Carthago Nova "la ciudad más importante de ese tramo litoral", al decir del geógrafo de Amasis, esconden también otra serie de limitaciones y dificultades para el desarrollo del hábitat, algunas de las cuales pudieron ser en parte solventadas en el marco del proyecto urbano de gran envergadura diseñado por Asdrúbal con claros deseos de continuidad, cuando institucionalizó con la fundación de Qart Hadasht, una situación de frecuentación de la zona preexistente, potenciando al máximo sus condiciones portuarias, sus relaciones con la metrópolis africana, su función estratégica por su carácter de bastión bien defendido y, sobre todo, la explotación de la plata del entorno próximo, aspectos todos bien resaltados por Polibio y los historiadores que, en gran parte, lo utilizan como fuente.

25 FERnÁNDEZ ET ALII 2007, 142.

26 Ramallo - Ruiz 2010, 104. 

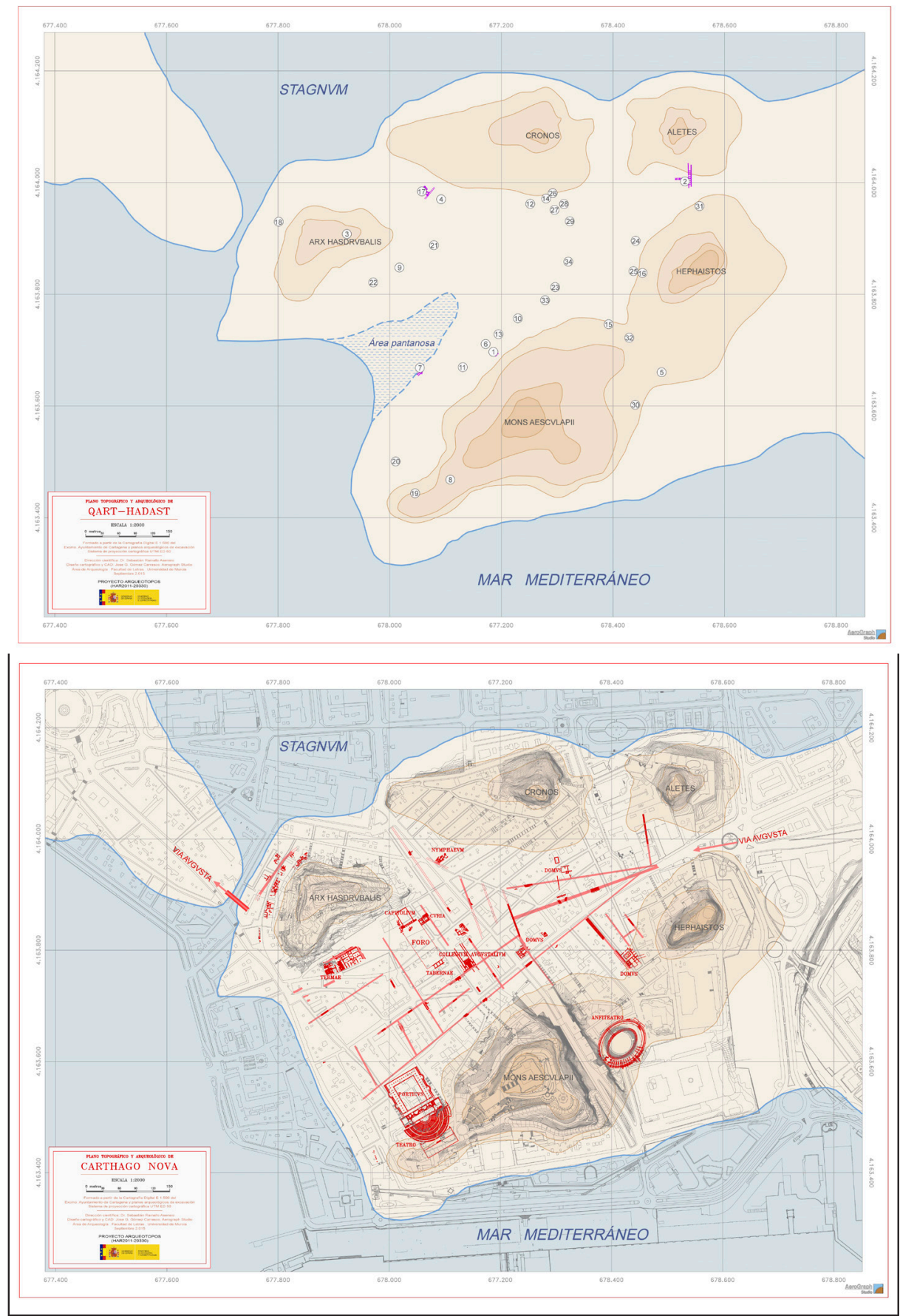

Fig. 4. A) Hipótesis de restitución de la topografía de Qart Hadasht. B) Carthago Nova en el s. I d. C. (Archivo Proyecto Arqueotopos) 
Los estudios geotectónicos, geomorfológicos, hidrológicos y de paleotopografía que hemos realizado entre 2012 y 2014 sobre el solar que acogió la urbe y su territorium, avanzan un medio físico definido por un sector elevado a modo de península, prolongación de los cerros de la Sierra de Cartagena-La Unión con la que se comunica por el este siguiendo la cota a media altura de la pendiente norte del Cerro de Los Moros. El rejuego de una serie de fallas de dirección noroeste-sureste y aproximadamente esteoeste compartimentaron dicho sector elevado, materializando cinco elevaciones de altura desigual que definen y realzan desde el exterior el perfil topográfico de la península en sus flancos septentrional y meridional mediante fuertes pendientes, $\mathrm{y}$ toda una serie de ramblas canalizadoras de una diversificada red hídrica interior, distribuidora de las aguas de escorrentía de las pendientes internas de los citados cerros circundantes hacia un valle de desarrollo este-oeste, confluyente en un bajo sector inundable de origen tectónico en el sector más occidental y abierto de la península. (Fig. 4).

Ahora sabemos con datos fiables que el fuerte gradiente de las laderas interiores, sobre todo del Cerro de la Concepción aunque también en las occidentales de Monte Sacro y Molinete, junto con los efectos de la red hídrica interior aludida, condicionaron la orientación de los principales ejes viarios y la configuración singular de los espacios urbanos públicos pero también de los privados. Las evidencias proporcionadas por los testigos de los sondeos geotécnicos practicados dentro de la ciudad en el marco del Proyecto Arqueotopos, dibujan claramente rellenos intencionales originados en depósitos de ladera en conjunción con una importante remodelación del medio natural con el objetivo de adecuar espacios originariamente no aptos para uso urbano. Las roturas geotectónicas que muestra el espacio intramoenia, la desigual altura y volumen de sus cinco colinas que constriñen de forma desigual el espacio a urbanizar, determinan en el sector oriental de la misma un primer espacio elevado, de superficie dispar, que desde la zona de acceso a la ciudad se prolonga hasta la altura de la actual Plaza del Risueño apoyada fundamentalmente en el piedemonte noroeste del Cerro de la Concepción; a partir de este horst se precipita una zona tectónicamente hundida por sendas fallas que con dirección este-oeste se alinean en la baja ladera septentrional del Cerro de la Concepción y la suroeste del Molinete respectivamente; la fuerte escorrentía de ramblas y ramblizos ligados al desarrollo en el tiempo de la red hídrica interna ya aludida, vertían de forma recurrente a este bajo sector en el que se reprodujo un medio salobre, de carácter cenagoso o pantanoso, hasta su definitivo saneamiento mediante la construcción de infraestructuras hídricas necesarias para canalizar los aportes torrenciales vinculados a un régimen pluviométrico irregular propio del período Húmedo Íbero-romano caracterizado paleoambientalmente para este período y los subsiguientes en la laguna de Zóñar $^{27}$ y contextualizado en el desarrollo de determinadas infraestructuras hídricas de la ciudad. ${ }^{28}$

En función de los datos ahora obtenidos, que insisten en un medio natural difícil en lo que al interior de la ciudad afecta, la adecuación y ampliación del espacio susceptible de urbanización debió de comenzar ya con la fundación de la ciudad por Asdrúbal, dentro de un proyecto urbanístico unitario predefinido, y en paralelo a la

27 Martín-Puertas ET ALII 2009.

28 Ramallo - Ros, 2012. 
construcción del cerco defensivo cuyas trazas se conservan en la pendiente meridional del Cerro de San José, protegiendo la entrada de la única conexión de la ciudad con el anteriormente citado entorno elevado de la Sierra de Cartagena; como anteriormente se ha adelantado, otro tramo de dicha cerca se localizó durante los trabajos de recuperación del Teatro Romano en la zona alta de la ladera noroeste del Cerro de la Concepción, una zona naturalmente defendida por los escarpes naturales del propio cerro, donde el paramento, visible desde el mar, insiste en el carácter simbólico que en la concepción urbana tenía la muralla. La adecuación topográfica de los viarios en los espacios en pendiente se realizó mediante potentes muros de aterrazamiento construidos en opus africanum y en aparejo en damero, alternativamente, como ilustran los tramos encontrados en distintos solares de la falda septentrional de este mismo cerro. Entre estos es especialmente interesante el excavado en la Plaza de San Ginés en $1986,{ }^{29}$ donde una calzada de tierra apelmazada sobre una base de cantos y guijarros, de 4,5 $\mathrm{m}$ de anchura, es fosilizada en su trazado, previamente recrecido por un relleno, por la calle romana enlosada de c. $3 \mathrm{~m}$ de anchura, integrada dentro del proceso de reordenación de la trama augustea, una medida que se reproduce en otro tramo de decumano descubierto en la calle Ciprés n. $7 ;^{30}$ una adecuación similar se detectó en el solar de la calle Cuatro Santos, esquina calle Palas, en este caso como fundamento del decumano.

No obstante, uno de los rasgos distintivos de esta trama viaria en relación con la entonces difícil topografía del solar primigenio es la disparidad de medidas que existe entre los distintos ejes, con anchos de vía que van desde los 4,50 m que alcanza uno de los cardos que asciende por la vaguada situada entre los Cerros de la Concepción y Despeñaperros para dar servicio a un barrio de carácter doméstico situado junto al anfiteatro, a los 3,10 m del cardo identificado en la calle Jara n. 10, ubicado en el extremo opuesto de la ciudad, cuya prolongación bordearía en rampa ascendiente el brazo oriental de la porticus post scaenam del teatro. Estas diferencias, que incluso son visibles en el recorrido de un mismo eje viario, se aprecian también en los decumanos; uno de ellos, con una orientación noreste-suroeste e identificado en varios puntos de su trazado, tiene una anchura de entre 5 y 5,50 $\mathrm{m}$ de anchura y desemboca directamente en las puertas de entrada a la ciudad, transformándose en el eje urbano de la vía Augusta. ${ }^{31}$ Debió de concebirse como uno de los ejes principales de la malla augustea, ya que tras discurrir en la mitad oriental de la ciudad con una dirección este-oeste, se dirigía hacia el borde septentrional de la fachada marítima, situado en el borde occidental de la ciudad, sin que podamos de momento determinar cómo se establecía su contacto con el foro. Es precisamente este cambio de sentido y divergencia en la orientación de la trama viaria entre la mitad oriental y la occidental, sin duda provocado por esa topografía original acabada de indicar, la que define el urbanismo de la ciudad durante los siglos II y I a.C., un urbanismo renovado que comienza a desarrollarse en el tercer cuarto del siglo I a.C. y que se prolonga hasta plena época augustea, de forma similar a lo que debió de ocurrir con la construcción

29 Martín - RoldÁN, 1997.

30 VIDAL ET ALII 2006, 182.

31 Martínez 2004, 203. 
del cerco defensivo. ${ }^{32}$ Con la información disponible es difícil seguir en el tiempo el proceso de construcción de la nueva trama viaria, ya que es escasa la información de los contextos subyacentes a la calzada enlosada. En algunos puntos esos niveles vienen definidos por la presencia mayoritaria de las producciones postreras de la cerámica de barniz negro y por la ausencia de terra sigillata aretina, lo que podría indicar una datación anterior al año 30 a.C.; sin embargo, no hay que descartar que en algunos puntos de la ciudad esa cronología pueda ser algo posterior y entrar ya en plena época augustea.

En su conjunto, la malla urbana muestra, en la mitad oriental de la superficie urbanizada, una convergencia de los ejes viarios en la puerta situada entre los montes de San José y Despeñaperros, desplegándose en abanico hacia la zona central del valle y adaptándose al progresivo desnivel que en dirección este-oeste impone el horst o sector elevado entre los cerros de la Concepción, Despeñaperros, San José y Sacro. Por el contrario, en la mitad occidental, entre las faldas meridional del Molinete y septentrional del Cerro de la Concepción la superficie existente se ensancha de forma notable, lo que permitía proyectar un trazado más regular, sin que se pueda hablar de una planificación ortogonal a escuadra y cordel e insulae de dimensiones regulares y constantes por toda la superficie; aquí el trazado urbano parece obedecer más bien a una necesaria adaptación a los límites norte y sur que imponen las pendientes de las laderas de Concepción y Molinete en esta área, incididas por sendas fallas de desarrollo este-oeste que compartimentan el bajo sector inundable centro-meridional. Con estos datos, parece claro que en este sector, donde tras la instauración de la colonia y, sobre todo en época augustea, se levantarán los principales espacios cívicos, hubo que emprender importantes trabajos de relleno para colmatar dicho sector hundido y fácilmente inundable que, al menos en determinados momentos, ocupaba lo que hoy es la moderna Plaza de San Francisco, parcialmente ocupada en época romana por la plaza forense enlosada, y zonas colindantes hacia el oeste. En este sentido, los sondeos realizados en la zona indican que procesos de colmatación, como el que en época augustea se materializó a gran escala, ya se habían producido en tiempos precedentes a la conquista romana, tanto con carácter natural como por acción antrópica.

Esta irregularidad en la malla urbana se percibe en la separación que existió entre los distintos ejes viarios; así, los decumanos descubiertos en las calles de San Francisco y San Antonio el Pobre, quedan separados por 29,60 m de distancia (100 pies); la misma tendencia se aprecia en las distancias existentes entre tres cardines del barrio del anfiteatro, cuya remodelación posiblemente corresponda a época augustea; cuarenta y cinco metros, o 150 pies, es la distancia que existe entre el muro exterior de las tabernae, que cierran el lado meridional del foro, y el decumano de la calle San Francisco; por otra parte, $59 \mathrm{~m}$ aproximadamente (c. 200 pies) es la distancia que existe entre los cardines de las calles Jara y Palas. No obstante, todos estos parámetros son aproximados ya que se parte de la imprecisión en la ubicación de muchos hallazgos dado que hasta los últimos años estos no han sido georreferenciados con coordenadas absolutas UTM. Esta asimetría del entramado urbano es sin duda el

32 Ramallo 2003; Díaz 2008, propone una datación de mediados del s. I a.C. para algunos de los epígrafes que aluden a la construcción del cerco defensivo. 
reflejo de una accidentada topografía, y la necesidad de adecuar laderas y colmatar espacios bajos intermedios para trazar las calles, acondicionar terrazas en laderas y crear las plataformas que requerían los grandes espacios públicos; en este sentido, la acotación de los restos de la fase augustea en distintos puntos de la ciudad permite constatar un claro proceso de declive en dirección noreste-suroeste y sur-norte, con diferencias tan notables que van desde los 6,64 m.s.n.m del tramo de decumano hallado en calle Duque 8-12 -vía urbana que discurre paralela a las actuales calles San Diego, Duque y Cuatro Santos por la falda de los cerros de Despeñaperros con una acusada inclinación hacia el oeste- a los 3,97 m del tramo paralelo -aunque desplazado hacia el oeste- descubierto en calle San Francisco 16-22, y los 3,47 m del eje siguiente atestiguado en San Antonio el Pobre. Estas diferencias de nivel se producen en los aproximadamente $65 \mathrm{~m}$ de distancia que separan estos tres decumanos y que vendrían a englobar dos insulae.

Esta misma disposición escalonada de las estructuras se aprecia en el complejo forense, configurado en su aspecto definitivo en época augustea. En este caso, los recursos topográficos se potencian al servicio de una escenografía que enfatiza la terraza del extremo septentrional, de $35 \mathrm{~m}$ de anchura, encajada en la falda meridional del Cerro del Molinete y sobre-elevada dos metros respecto a la contigua, donde debía de ubicarse el templo o principal espacio de culto de la ciudad. Dos escaleras simétricas de doce peldaños, que a su vez delimitan cuatro contrafuertes o basamentos intermedios, permiten salvar el desnivel y comunican con la terraza intermedia, destinada probablemente a usos de carácter civil; por último, y a un nivel más bajo, la plataforma enlosada de la plaza, que alberga las funciones mundanas y se cierra en el borde meridional por una serie de tabernae con los vanos abiertos hacia el interior. ${ }^{33}$ En su conjunto, el foro se proyecta como un espacio rectangular de, aproximadamente, $85 \mathrm{~m}$ de longitud por $40 \mathrm{~m}$ de anchura, con una orientación noroeste-sureste y cerrado lateralmente por un doble pórtico. Restos de una inscripción con litterae aureae nos aporta el nombre de uno de los evergetas que, al menos, contribuyó a la financiación de plaza. El texto conserva sólo las letras $A P$ [---], precedidas por una interpunción, lo que permitía relacionarlo, al menos de forma hipotética, con el cognomen Apalus que porta el magistrado C. Laetilius, quien firma, en su condición de duunviro quinquenal y con el rey de Numidia y Mauritania Ptolomeus como colega, una acuñación que se tiende a fechar entre los años 12-13 d.C. ${ }^{34}$ Este personaje es, probablemente, el mismo que aparece como indicación cronológica, en virtud de su condición de quinquenal, en una inscripción donde piscatores et propolae dedican una columna de travertino rojo a los lares augustales y Mercurium..$^{35}$ Se ha señalado la posible vinculación de este personaje con un Laetilius Ferm [---] que aparece recogido en los lingotes de plomo, relacionando los recursos económicos de esta familia con la explotación de las minas de Carthago Nova; el magistrado podría haber sido un descendiente de los libertos de esta gens enriquecidos con esta actividad. ${ }^{36} \mathrm{Su}$

33 Berrocal 1987, 141, fig. 3.

34 Llorens 2002, 69. Beltrán 1949, propuso una datación del año 14 d.C. para esta acuñación.

35 Abascal - Ramallo 1997, 161-164, lám. 42.

36 Domergue 1985, 201; КосH 1988, 404. 
carrera, de ser el mismo personaje, cosa incierta, se podría restituir gracias al texto inscrito sobre el pedestal de una estatua ecuestre, que probablemente debió de estar situada en el foro, dedicada a C(aio) Laetilio M(arci) $f$ (ilio) tras su muerte por los coloni et incolae de la ciudad; así, sabemos que fue pontifex y ocupó de forma progresiva el edilato, el duunvirato y el duunvirato quinquenal, magistraturas habituales en un cursus honorum decurional. ${ }^{37}$ (Fig. 5) No obstante la vinculación de todas estas evidencias a un mismo personaje, a pesar de la aparente coincidencia cronológica, no deja de ser una propuesta hipotética, aunque con fuertes visos de realidad. En cualquier caso, todas ellas redundan en la actividad evergética y el dinamismo edilicio de la ciudad en época augustea.

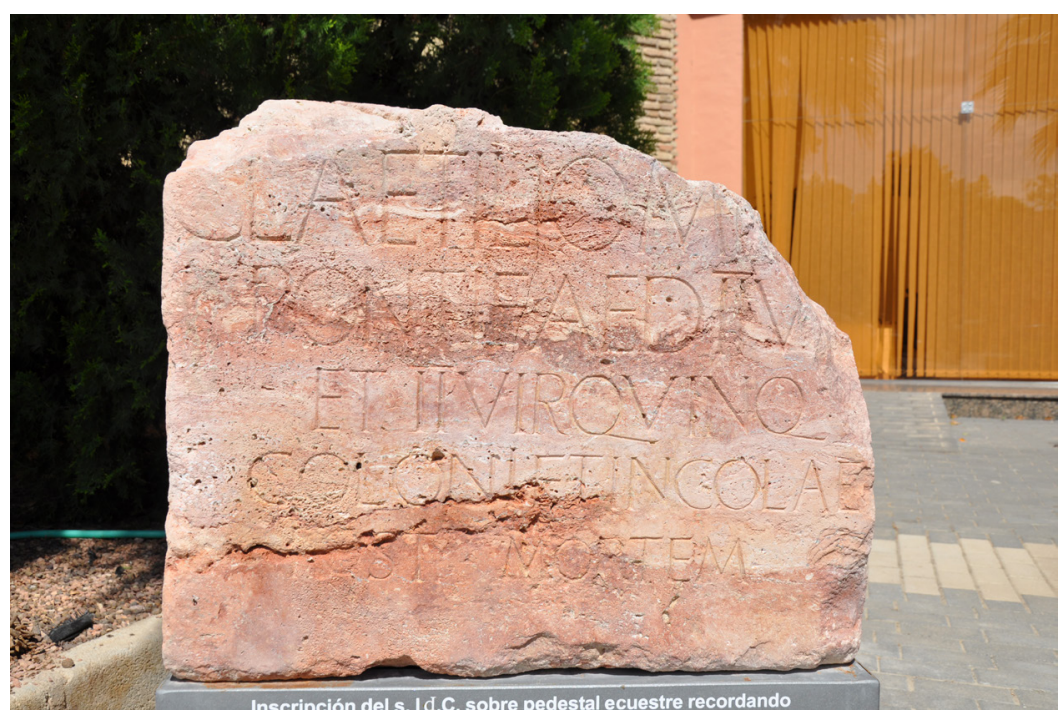

Fig. 5. Pedestal en travertino rojo de estatua ecuestre, dedicado a M. Laetilio Apalo.

En cualquier caso, y a pesar de los hallazgos monumentales que se han ido produciendo en las dos últimas décadas del siglo XX, aun son muchos los interrogantes que planean sobre el más destacado espacio público de la ciudad, su planteamiento original y evolución. ${ }^{38}$ La configuración inicial del foro debió de sufrir una serie de alteraciones a lo largo del siglo I d.C., con la incorporación progresiva de nuevos equipamientos públicos que, probablemente, alteraron la trama original de los ejes viarios. La primera de estas evidencias se manifiesta en la anulación del decumano que discurría ante la terraza más septentrional del complejo forense, donde -como ya hemos señalado más arriba-, se debía levantar el templo que presidía la plaza, por la construcción o recrecido de la segunda terraza, lo que supone la ocultación de

37 ABASCAL 2009.

38 Una recopilación exhaustiva de todas las noticias y hallazgo de esta zona central del núcleo urbano han sido recogidas en NoGUERA ET ALII 2009. 
los peldaños inferiores de las escalinatas de acceso a la plataforma superior. ${ }^{39}$ En el extremo nororiental de esa terraza, delimitado al norte por la calzada mencionada y al este por un cardo con proyección noroeste-sureste, se construye un edificio público de planta rectangular identificado como la curia ordinis. ${ }^{40}$ El edificio se articula en dos sectores, una sala cuadrangular interior de $88,36 \mathrm{~m}^{2}$ de superficie, tapizada con un rico opus sectile, donde se dibujan los dos espacios que definen estos edificios, vestíbulo junto a la puerta y aula, precedida por una especie de atrio con cuatro columnas centrales, que ahora se puede parangonar con el atrio tetrástilo que antecede la sala en la curia de Torreparedones; ${ }^{41}$ reforzaría esta relación la existencia en Cartagena de un acceso lateral en el flanco sur que comunicaría con una estancia contigua desde el atrio, tal y como vemos sucede en la población cordobesa. El hallazgo en el interior de la sala de Carthago Nova de un togado capite velato de tamaño mayor que el natural, que, probablemente y al menos en un primer momento, sustentaría un retrato del propio Princeps como pontifex, ha servido como argumento para proponer una datación tardo-augustea para el edificio, ${ }^{42}$ si bien determinados detalles arquitectónicos y de su programa ornamental han sugerido adelantar su cronología a época flavia. ${ }^{43}$

En este mismo flanco lateral del foro, aunque más hacia el sur, se dispone un edificio termal de grandes dimensiones, que interrumpe el recorrido de un cardo que, con una dirección noroeste-sureste, ha sido identificado en varios puntos a ambos lados del establecimiento balnear. La cronología de este importante complejo es difícil de definir, aunque se ha sugerido una datación en la primera mitad del siglo I d.C. para el edificio, aunque sin argumentos concluyentes. ${ }^{44}$ Los cambios en este lado de la plaza, que son a su vez testimonio de la vitalidad edilicia a largo del siglo I d.C. se manifiestan en el edificio que cierra el ángulo suroriental del espacio público, tradicionalmente identificado como sede del collegium augustalium o Augusteum, ${ }^{45} \mathrm{y}$ fechado a finales del siglo I d.C., que anula parcialmente el extremo del porticado que desde finales del siglo I a.C. se disponía tras el flanco sur de la plaza y en posición transversal.

Más allá del ámbito público, en los espacios domésticos, la renovación urbana de la ciudad en época augustea se manifiesta también en la incorporación a las viviendas de técnicas y estilos decorativos vigentes en Roma y en el área campana de forma contemporánea. Tal es el caso de las pinturas del III Estilo de la denominada domus del Sectile, emplazada en el barrio residencial situado al este del anfiteatro, en la falda septentrional del Cerro de Despeñaperros, ${ }^{46}$ caracterizada como rasgo distintivo por la reproducción pintada de un candelabro metálico; otro panel que se podría encuadrar en este mismo estilo procede de una domus identificada en la calle del Ángel, aunque en este caso se carece de contexto arqueológico, ya que los fragmentos fueron

39 Roldán - De MiQuel 1999, 58.

40 Martín 2006.

41 MÁrquez ET ALII 2014, 78, fig. 15.

42 Ruiz - De Miquel 2003.

43 Noguera ET ALII 2009, 274.

44 SuAREZ 2011.

45 De Miquel - Subías 1999; Noguera 2002.

46 Fernández 2008, 149, lám. 21. 
recuperados al realizar una zanja para infraestructuras urbanas. ${ }^{47}$ Corresponden también a esta fase de remodelación urbana los últimos pavimentos de opus signinum decorados con teselas blancas y negras, insertas en esquemas y composiciones de cierta complejidad. No obstante, junto a estas, que suelen cubrir los suelos de habitaciones de mayores dimensiones, perviven aún los esquemas más sencillos, como las crucetas alineadas de cuatro teselas blancas en torno a una negra que vemos en el solado de una vivienda, posiblemente augustea, de la Plaza San Ginés. ${ }^{48}$

Al margen de la discusión sobre el origen púnico o itálico de este sistema de pavimentación -de momento no podemos establecer ninguna relación de continuidad entre los fragmentos de pavimento de la muralla púnica de La Milagrosa, formados por una mezcla de cerámica machacada, abundante cal y gravilla, que evocan con claridad los pavimentos de signinum, y los más antiguos ejemplos de la ciudad romana-, parece por el contrario más acertado pensar que la introducción en la ciudad de este sistema de pavimentación, al menos desde finales del siglo II a.C., corresponde a la llegada de artesanos especializados procedentes de la península itálica; a partir de este momento, su uso se extiende tanto en la arquitectura pública como privada, y se prolonga, por lo menos, hasta época augustea. La supuesta domus de la Fortuna, así designada por la advocación Fortuna propitia inscrita sobre uno de sus pavimentos, ofrece un ejemplo excepcional de esta arquitectura doméstica -o privada- en la ciudad hacia el cambio de era. En este caso, y a diferencia de la denominada casa de Salvius, que antes comentábamos, donde atrio y peristilo constituyen dos piezas esenciales en el organigrama de la casa, en la de la Fortuna, el acceso principal da paso a una amplia estancia interpretada como vestíbulo/atrio, tal vez testudinado, junto a la cual se inserta en uno de los ángulos del inmueble una habitación de grandes dimensiones -tal vez un triclinium de ser correcta la identificación como domus- tapizada con un opus signinum donde se yuxtaponen cartones con motivos diferentes: reticulado de rombos, meandros de esvásticas y cuadrados, estrella de ocho rombos inscrita en un círculo, que delinean los distintos espacios para la colocación del mobiliario en el interior de la estancia.

En el ámbito funerario, la época augustea se manifiesta en una generalización del hábito epigráfico que se plasma en el incremento notable del número de epitafios y en la difusión de ciertos monumentos que caracterizan la arquitectura funeraria itálica del momento. Ahora bien, si disponemos de un elevado número de inscripciones funerarias que pueden ser datadas en época augustea, nuestro conocimiento de las áreas sepulcrales donde debieron estar ubicadas es mucho más impreciso. En este caso, la topografía del entorno de la ciudad y, sobre todo, la existencia de amplios sectores pantanosos o fácilmente inundables en determinadas fases del año condicionaron su emplazamiento. No obstante, a nivel espacial, podemos situar con cierta precisión su ubicación y establecer unos marcos cronológicos para el desarrollo de cada una de ellas; por el contrario, caracterizarlas a nivel monumental y tipológico resulta mucho más complicado. Las necrópolis de época augustea se emplazan al oriente de la ciudad; flanqueando la vía Augusta, que desciende por el litoral mediterráneo, en

47 Fernández 2008, 153, lám. 23.

48 Martín - Roldán 1997, 127. 
un caso, y junto a la costa, en un recodo que la bahía de Cartagena hace al sureste de la ciudad. La primera es la de la Torre Ciega, denominación que toma del único monumento funerario mejor conservado hasta la actualidad, un sepulcro de tipo turriforme compuesto por dos cuerpos superpuestos, el inferior en forma de prisma cuadrangular, con zócalo, cornisa y paredes revestidas de opus reticulatum, sobre el que se levanta un cono truncado y rematado por un casquete semicircular, desaparecido desde comienzos del siglo XVIII; no obstante, el paralelismo con las torres funerarias de la necrópolis de Avellino (Campania) permite corroborar la veracidad de los dibujos completos que del monumento se conservan. Al margen del monumento, que probablemente habría que fechar en el último tercio del siglo I a.C., sino unos pocos años antes, las urnas cinerarias, entre las que conviven receptáculos de vidrio protegidos en urnas de plomo, con otros de cerámica pintada de tradición ibérica, y los materiales procedentes del ajuar permiten ofrecen un marco cronológico entre la segunda mitad del siglo I a.C. y la primera mitad de la centuria siguiente para el desarrollo de este cementerio. ${ }^{49}$

La segunda necrópolis es la de Santa Lucia, en el entorno del actual barrio de pescadores levantado en parte sobre un promontorio rocoso, que debió de constituir el soporte para la inserción de panteones de carácter hipogeico, como el descubierto hacia 1781 "en las inmediaciones del muelle de Santiago". Se trata de una sepultura de planta rectangular, dotada de bancos o poyos adosados a las paredes, y precedida por un corredor de acceso inclinado. Una lápida asociada al panteón permite en parte precisar las dimensiones de la sepultura y la posible origo del individuo enterrado; los arcaísmos del texto podrían sugerir una datación a finales de la República, si bien la mención de la procedencia nos introduciría a comienzos del Imperio. Hay noticias de otros panteones en esta necrópolis, pero de ellos sólo se han conservado las sepulturas y desconocemos su estructura y fábrica. Al margen de estas dos necrópolis, se conocen otros testimonios de carácter funerario a poniente de la ciudad, si bien su adscripción cronológica y contextualización es más difícil, ya que salvo casos excepcionales las evidencias se restringen a los epitafios descontextualizados.

En conjunto, el intenso programa de renovación urbanística y monumental de la ciudad iniciado hacia mediados del siglo I a.C., se consolida en sus componentes básicos en época augustea y se prolonga, con la adición de nuevos equipamientos o la restauración y remodelación de los antiguos, a lo largo del siglo I d.C. y las primeras décadas de la centuria siguiente. Es probable que a época augustea correspondan los intentos de ampliación de los espacios susceptibles de urbanización mediante la colmatación de sectores periféricos y en contacto con las áreas inundables, preferentemente en los márgenes de la lengua de tierra por donde discurría la calzada que conducía hacia el interior del conventus. Sin duda también contribuyó al desarrollo de ese momento la potenciación de la vía Augusta, pavimentada, según los miliarios, entre los años 8-7 a.C..$^{50}$

Sin embargo, y como contrapartida, la paralización en algunos casos o ralentización de la actividad minero-metalúrgica, que había estado en la base de las principales

49 Ramallo - Ros 2013, 316.

50 Martínez - Ponce 2014, 65. 
fortunas de época tardorrepublicana, supuso un importante revés para el desarrollo económico de la ciudad y de la zona, imponiendo la búsqueda de actividades alternativas, las cuales, en ningún caso, podrán llegar a suplantar a los ingentes recursos obtenidos de la explotación de las ricas minas de plata del entorno de la ciudad.

\section{BibLIOGRAFÍA}

Abascal, J. M. (2009): "Pedestal ecuestre para C. Laetilius M. f. en Carthago Nova (Hispania Citerior)", Mastia 8, 103-113.

Abascal Palazón, J. M. - Ramallo Asensio, S. F. (1997): "La ciudad de Carthago Nova: la documentación epigráfica", [en] La ciudad romana de Carthago Nova: fuentes y materiales para su estudio, vol. 3, Murcia.

Amela Valverde, L. (2012): "Precisiones al recientemente descubierto epígrafe de Cn. Pompeyo Magno en Carthago Nova", Espacio, Tiempo y Forma, Serie II, Historia Antigua 25, 191-206.

Beltrán Martínez, A. (1949): "Las monedas latinas de Cartagena”, Anales de la Universidad de Murcia, curso 1948-1949 (segundo semestre), 149-186.

Berrocal Caparrós, M. C. (1987): "Nuevos hallazgos sobre el Foro de Carthago Nova", [en] Los foros romanos de las provincias occidentales, Madrid, 137-142.

Broise, P. (1969): “Eléments d'un ordre toscan provincial en Haute-Savoie”, Gallia 27/1, $15-22$.

Centerini, G. (2010): “Gaio e Lucio Cesari, nipoti e successori di Augusto: la documentazione occidentale”, Rivista storica dell'antichità 40, 109-136.

DiAZ ARIÑo, B., (2008): "Las murallas romanas de Cartagena en la segunda mitad del siglo I a.E.", Zephyrus 41/1, 225-234.

Domergue, C. (1985): “L'explotation des mines d'argent de Carthago Nova: son impact sur la structure sociale de la cité et sur les depenses locales a la fin de la République et au debut du Haut-Empire", [en] Ph. Levau (ed.), L'origine des richesses depensées dans la ville antique, Aix, 197-217.

FERnÁNDEZ DíAz, A. (2008): El programa pictórico de los edificios públicos y privados del área de Carthago Nova y su entorno, Murcia.

Fernández Matallana, F. - Zapata Parra, J. A. - Nadal Sánchez, M. (2007): "Excavación arqueológica en la calle Mayor esquina Medieras de Cartagena", [en] XVIII Jornadas de Patrimonio Cultural, Murcia, 141-143.

Gros, P. (1990): “Théâtre et culte impérial en Gaule Narbonnaise et dans la Péninsule ibérique", [en] W. Trillmich - P. Zanker (eds.), Stadtbild und Ideologie. Die Monumentalisierung hispanischer Städte zwischen Republik und Kaiserzeit, München, 381-390.

$\mathrm{KocH,} \mathrm{M.}$

(1988): "Las "grandes familias" en la epigrafía de Carthago Nova", [en] Actas del 1er congreso península de Historia Antigua (Santiago, 1986), Santiago, 403-407.

(2009): "Noch einmal: die "grossen Familien" in Carthago Nova", MM 50, 158-171.

LlORENS ForCADA, M. M. 
(1994): "La ciudad romana de Carthago Nova: las emisiones romanas", [en] La ciudad romana de Carthago Nova: fuentes y materiales para su estudio, vol. 6, Murcia. (2002): "Carthago Nova: una ceca provincial romana con vocación comercial", Mastia 1 , 45-76.

Madrid Balanza, M. J. - Celdrán Beltrán, E. - Vidal Nieto, M. (2005): “La domus de Salvius. Una casa de época altoimperial en la calle del Alto de Cartagena. (PERI CA-4/ Barrio universitario)", Mastia 4, 117-152.

Marquez, C. - Morena, J. A. - Córdoba, R. - Ventura, A. (2014): Torreparedones. Investigaciones arqueológicas (2006-2012), Córdoba.

Martín Camino, M. (2006): "La curia de Carthago Nova", Mastia 5, 61-84.

Martín Camino, M. - Roldán Bernal, B. (1997): "Plaza de San Ginés número 1 esquina calle del Duque", [en] Memorias de Arqueología. Excavaciones arqueológicas en Cartagena, Murcia, 126-128.

Martínez SÁnchez, M. A. (2004): "El Decumano Máximo de Carthago Nova: la calzada de la calle San Diego", Mastia 3, 195-204.

Martín-Puertas, C. - Valero-Garcés, B.L. - Brauer, A. - Mata, M. P. - Delgado-Huertas, A. - Dulski, P. (2009): "The Iberian-Roman Humid Period (2006-1600 cal yr BP) in the Zóñar Lake varve record (Andalucía, southern Spain)”, Quaternary Research 71, 108-120.

Martínez Rodríguez, A. - Ponce García, J. (2014): "El descubrimiento de un nuevo miliario en el Hornillo, Lorca (Murcia)", Alberca 12, 59-72.

De Miquel Santed, L. E. - Subías Pascual, E. (1999): "Un edificio de culto en la calle Caballero (Cartagena)", [en] XXIV Congreso Nacional de Arqueología, Murcia, 49-56.

Monterroso ChecA, A. (2010): "La scaenae frons en los teatros de Roma, entre liturgia, forma y modelos", [en] S. F. Ramallo Asensio - N. Röring (eds.), La scaenae frons en la arquitectura teatral romana, Murcia, 15-55.

Noguera Celdrán, J. M. (2002): “Un edificio del centro monumental de Carthago Nova. Análisis arquitectónico decorativo e hipótesis interpretativas, $J R A$ 15, 63-96.

Noguera Celdrán, J. M. - Soler Huertas, B. - Madrid Balanza, M. J. - Vizcaino SáMCHEZ, J. (2009): “El foro de Carthago Nova: estado de la cuestión”, [en] J. M. Noguera Celdrán (ed.), Fora Hispaniae, Paisaje urbano, arquitectura, programas decorativos y culto imperial en los foros de las ciudades hispanorromanas, Murcia, 213-298.

Perea Yébenes, S. (2005): "Elementos del cursus honorum cívico de un notable de Carthago Nova. ¿M. Postumius Albinus? Propuestas de interpretación”, Mastia 4, 65-86.

Ramallo Asensio, S. F. (2003): “Arqueología y epigrafía de la muralla urbana”, [en] A. Morillo Cerdán - F. Cadiou - D. Hourcade (eds.), Defensa y territorio de los Escipiones a Augusto: espacios urbanos y rurales, municipales y provinciales, León, 325-362.

Ramallo Asensio, S, F. - Ros Sala, M. M.

(2012): "La gestión del agua en una ciudad romana de la Hispania semiárida: Carthago Nova como ejemplo de adaptación al medio", [en] J. M. Gómez Espín - R. M. Hervás Avilés (coords.), Patrimonio hidráulico y cultura del agua en el Mediterráneo, Murcia, 77-104.

(2013): “Aportación inicial a una relectura integral de la necrópolis romana de Torre Ciega (Cartagena)", Mastia 9, 269-317.

Ramallo Asensio, S. F. - Ruiz Valderas, E. 
(1998): El teatro romano de Cartagena, Murcia.

(2010): "Carthago de Hispania: emporio comercial del Mediterráneo occidental”, [en] R. González Villaescusa - J. Ruiz de Arbulo (eds.), Simulacra Romae II. Rome, les capitales de province (capita provinicarum) et la création d'un espace commun européen. Une approche archéologique, Reims, 95-110.

Ramallo Asensio, S. F. - Murcia Muñoz, A. J. - Ruiz Valderas, E. (2010): “La scaenae frons del teatro de Carthago Nova", [en] S. F. Ramallo Asensio - N. Röring (eds.), La scaenae frons en la arquitectura teatral romana, Murcia.

Ripollés Alegre, P. P. - Abascal Palazón, J. M. (1999): "Varia metallica (III): análisis de monedes provincials romanes d'Hispania", Acta Numismatica 29, 49-58.

Roda De Llanza, I. (2004): “La figura de Agripa en Hispania”, [en] C. Pérez González - E. Illaregui Gómez, (coords.), Arqueología militar romana en Europa, Valladolid, 319-332.

Roldán Bernal, B. - De Miquel SAnted, L. (1999): "Excavaciones en el templo capitolino de Carthago Nova", [en] XXIV Congreso Nacional de Arqueología, vol. IV, Murcia, 57-65.

Ruiz Valderas, E. - De Miquel Santed, L. (2003): "Novedades sobre el foro de Carthago Nova: el togado capite velato de la calle Adarve", Mastia 2, 267-281.

Soler Huertas, B. (2014): "Planificación, producción y costo del programa marmóreo del teatro romano de Cartagena", [en] V. García-Entero (ed.), El marmor en Hispania: explotación, uso y difusión en época romana, Madrid, 193-228.

SuÁrez Escribano, L. (2011): "Hallazgo de un nuevo edificio público en Carthago Nova: Las termas del foro", Verdolay 13, 113-126.

Trunk, M. (2008): Los capiteles del foro de Segóbriga. Evolución tipológica y estilística, Cuenca.

Vidal Nieto, M. - Vizcaino SÁnchez, J. - Quevedo SÁnchez, A. (2006): “Un nuevo tramo de Decumano de Cartagena", AnMurcia 22, 181-192. 